\title{
The Research on the Power Emergency Data Exchange Technology
}

\author{
Weimei Zhao ${ }^{\mathrm{a}}$, Xiaofeng $\mathrm{Qu}^{\mathrm{b}}$, Yu Zhen ${ }^{\mathrm{c}}$ \\ State Grid Smart Grid Research Institute, Beijing, China \\ ae-mail: zhaoweimei@sgri.sgcc.com.cn, be-mail: quxiaofeng@sgri.sgcc.com.cn, `e-mail: yuzhen@sgri.sgcc.com.cn
}

\begin{abstract}
The power emergency data transmission and collection need to grasp the overall data and the interdepartmental data. Research on emergency data exchange technology is important for electricity emergency projects. This paper in-depth studies the power emergency data exchange technology. The author propose a vertical through the overall architecture of the power company headquarters emergency information platform and the provincial power company emergency command information platform for data exchange, and also propose the concept of data transmission, which based on data exchange platform and data center. And this paper also proposes the method of direct data exchange between the power company headquarters emergency information platform and provincial power company emergency information platform using the data exchange platform. Finally, the paper describes the transmission of formatted data and non-formatted data, also analyzes the exchange process of custom data.
\end{abstract}

Keywords-power emergency;command information platform;data exchange platform;data center;architecture

\section{INTRODUCTION}

Emergency command center is the power company's leaders and relevant departments to command each basic unit, which carry out a major place for emergency disposal. Currently the information sources of the emergency command center, mainly composed by the real-time monitoring emergency scene, the power grid, video consultation information, decision support information and other components. Emergency data exchange is an important part of emergency platform construction, to achieve interoperability of national and local governments, as well as the primary means of sharing information [1] - [2]. In this paper, we propose a program of emergency command information platform about the longitudinal through data, to provide a reference for the realization of the design and development of emergency platform.

\section{THE POWER EMERGENCY DATA EXCHANGE}

\section{A. Overall architecture}

Emergency command information platform between the power company's headquarters and the provinces can be achieved through longitudinal data and data integration. Provincial power companies through data exchange platform and data centers, achieve vertical integration of business applications data [3]-[4]. The overall architecture shown in Figure 1.

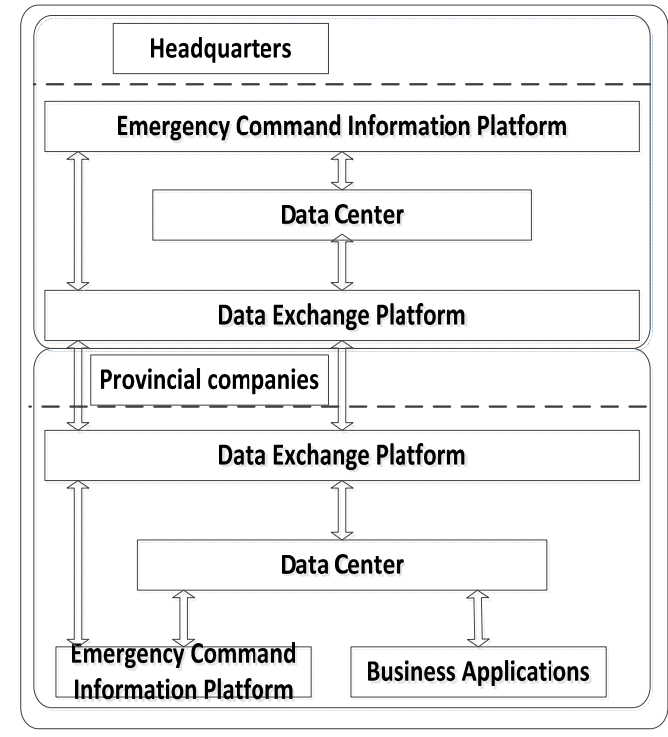

Figure 1. The diagram of data through general framework

Emergency Command Information Platform: receives various data transmitted from the data center, is the power company leaders and relevant departments directing each basic unit, to carry out an important source of information on major emergency management decisions; Data Center: a combination of various computer systems and other ancillary equipment, environmental control equipment, monitoring equipment, and various safety devices, etc., which receives data exchange platform transmitted information from the data; Data exchange platform: a distributed fashion deployed on front-end power company headquarters and the provincial power company for each application system, the platform according to the unified data exchange standards, unified interface, the unified transfer protocol, enabling different information free conversion between data repository, constitute automatic extraction and conversion power company headquarters and the provincial power company longitudinal data [5].

Use only the data exchange platform to achieve through longitudinal data for headquarters and the provincial power company emergency command information platform, because the platform for real-time data requirements are relatively high, the amount of data is small. Data-based data exchange platform and data center longitudinal through for headquarters and the provincial power business applications, because the platform less demanding real-time data and the data volume [6] - [7]. 


\section{B. The data exchange platform based on longitudinal through}

Emergency command information platform during operation, the data needed for real-time requirements are relatively high and a relatively small amount of data, it can be directly exchanged data exchange platform. There are two types of data exchange: Formatting and unformatted, data exchange platform using different exchange services to complete the exchange of data.

- Exchange formatted data (Exchanged between the table and the table): The provincial power company emergency command information platform, after calling access data exchange, data exchange to obtain data from the provincial power emergency command information platform, to exchange data and data exchange platform to the power transmission company headquarters data exchange platform. Data exchange platform power company headquarters, to write data to a temporary table power company headquartered emergency command information platform, and sends "data has arrived" notification to the notification queue, headquarters emergency command information platform for timely notification in accordance with this discrimination data, it has reached power company headquarters; If the data has reached the power company headquarters emergency command information platform, the platform will trigger data synchronization, from the temporary table to the official table[8] - [10].The data exchange format shown in Figure 2.

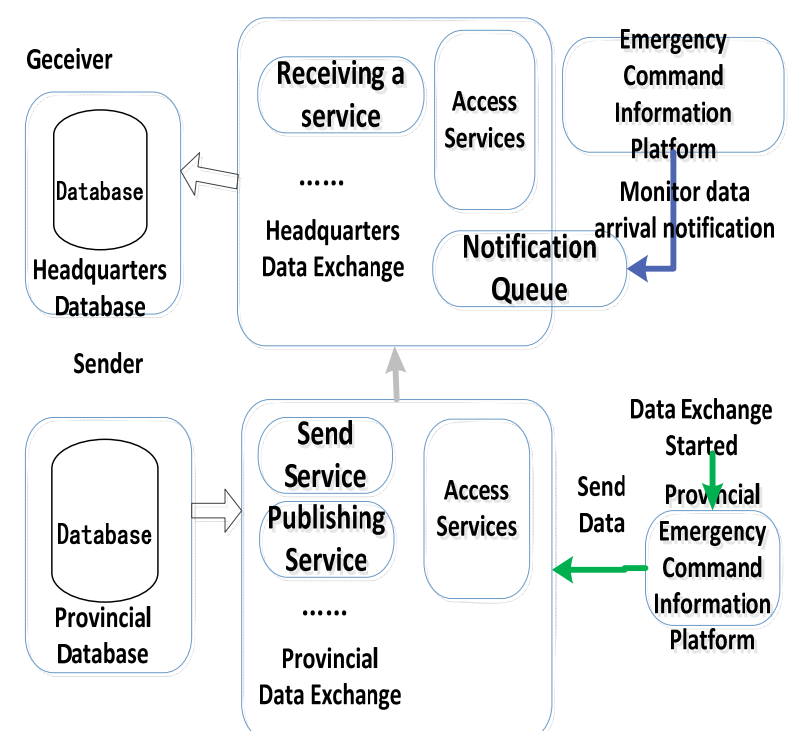

Figure 2. The exchange for formatted data

- Complete data exchange format provided that: In the data exchange platform, the configuration database and the headquarters of the provincial power company connection information (database type, address, and other information users), and open permission to read data in the provincial power company, open write access to the temporary table at the headquarters of the database. Data exchange unit involved in coding, you must reference unit encoded data exchange provided; Database table structure exchange between headquarters and the provincial power companies must be the same, and there must be required to include field which data exchange platform requirements. The provincial power company will provide an interface for data exchange platform service address, to the provincial power company's emergency command information platform; Headquarters will provide an interface for data exchange platform service address, to the headquarters emergency command information platform. Interface Description: Interface to access services as shown in Table 1.

TABLE 1. THE INTERFACE FOR ACCESS SERVICE

\begin{tabular}{|l|l|l|}
\hline Service Name & \multicolumn{2}{|l|}{ DXPAccessService } \\
\hline $\begin{array}{l}\text { parameter } \\
\text { name }\end{array}$ & Parameter Type & $\begin{array}{l}\text { Parameter } \\
\text { Description }\end{array}$ \\
\hline requestStr & String & Input parameters \\
\hline responseStr & String & return value \\
\hline $\begin{array}{l}\text { Function } \\
\text { Description }\end{array}$ & $\begin{array}{l}\text { Provide external data exchange } \\
\text { interface service description }\end{array}$ \\
\hline
\end{tabular}

\section{Unformatted data exchange}

- Exchanged between the table and the table: Provincial power companies will want to send a nonformatted data is read into the data stream, encapsulated into parameter object, in order to meet the provincial power company data exchange platform data access requirements. Meanwhile, the call to send the file in the data exchange access service module, to send data to the headquarters emergency command information platform. Headquarters emergency command information platform for the notification queue monitor data, found that data reaches, call the headquarters data exchange, access to data interface service reads [11], the exchange of non-formatted data as shown in Figure 3. 


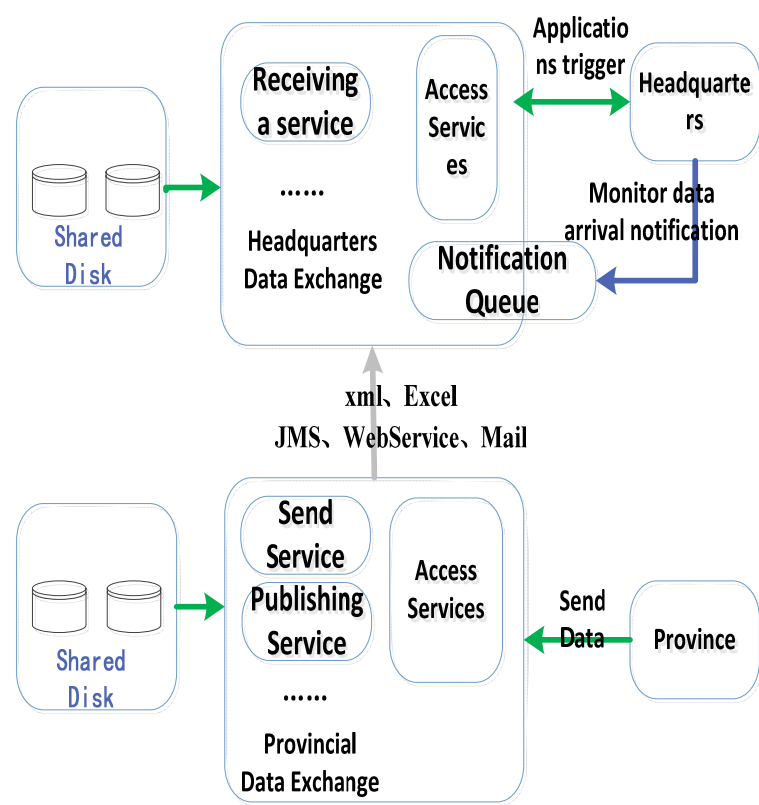

Figure 3. The exchange for non-formatted data

- The premise of unformatted for data exchange: The provincial power company data exchange platform, will provide the interface services address to the provincial power company emergency command information platform; Headquarters data exchange platform, providing information to headquarters emergency command platform interface service address; Import emergency command information platform relies on data exchange platform related library file, such as when sending a file, to be introduced in the package where DataHandler object activation.jar.

\section{INTERFACE DESCRIPTION}

Send a description of the service interface parameters are shown in Table 2, Table 3 for a file server interface parameter describes.

TABLE 2. THE INTERFACE FOR SEND SERVICE

\begin{tabular}{|l|l|l|}
\hline Service Name & \multicolumn{2}{|c|}{ Send Attach File } \\
\hline parameter name & \multicolumn{1}{|c|}{ Parameter Type } & $\begin{array}{c}\text { Parameter } \\
\text { Description }\end{array}$ \\
\hline requestStr & String & Input parameters \\
\hline fileObject & DataHandler & File Object \\
\hline responseStr & String return value \\
\hline $\begin{array}{c}\text { Function } \\
\text { Description }\end{array}$ & $\begin{array}{l}\text { Provide external data exchange interface } \\
\text { service description。 }\end{array}$ \\
\hline
\end{tabular}

TABLE 3. THE INTERFACE FOR FILE SERVICE

\begin{tabular}{|c|l|l|}
\hline Service Name & \multicolumn{2}{|c|}{ Get Attach File } \\
\hline parameter name & \multicolumn{1}{|c|}{ Parameter Type } & $\begin{array}{c}\text { Parameter } \\
\text { Description }\end{array}$ \\
\hline requestStr & String & $\begin{array}{l}\text { Input } \\
\text { parameters }\end{array}$ \\
\hline fileObject & DataHandler & return value \\
\hline $\begin{array}{c}\text { Function } \\
\text { Description }\end{array}$ & $\begin{array}{l}\text { Provide external data exchange interface } \\
\text { service description。 }\end{array}$ \\
\hline
\end{tabular}

\section{BASED ON THE DATA CENTER FOR LONGITUDINAL THROUGH}

In the provincial power company's business applications, data associated with the emergency services, and emergency command information generated by the platform itself, can be accomplished by a data center and a combination of data exchange. Vertical integration of data based on the data center for less demanding real-time exchange of data and the large amount of data. Based on the data center through the longitudinal shown in Figure 4.

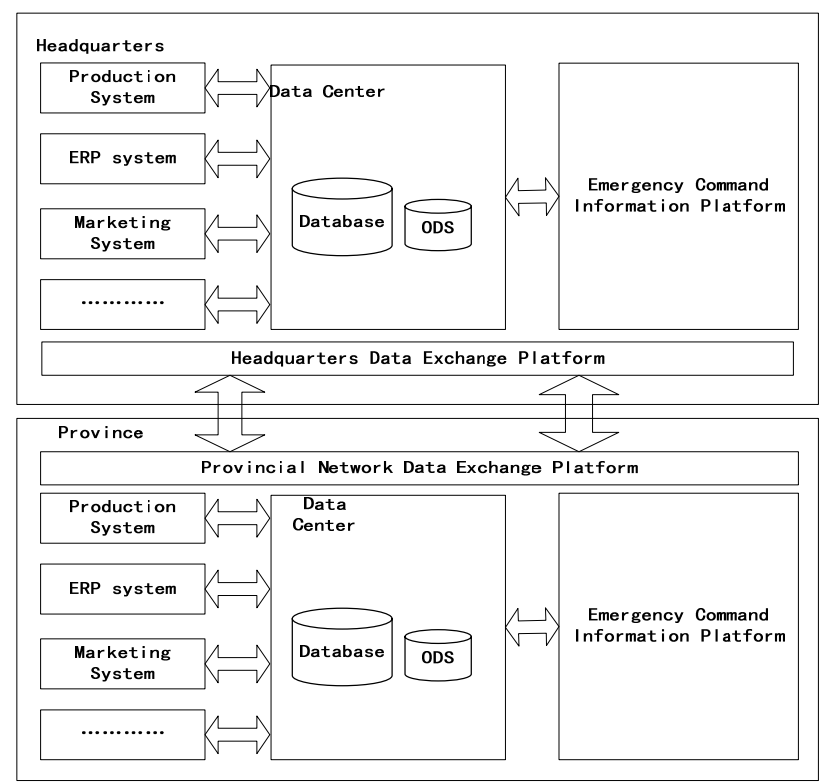

Figure 4. Data vertically through based on the data center

The provincial power company's data center to retrieve data from ODS after emergency command information platform, sent to the headquarters data exchange module, the headquarters data exchange module to write data to the ODS of the headquarters data center, the headquarters of the emergency command information platform to obtain data 
from the ODS [12] - [13]. The data exchange process is shown in Figure 5:

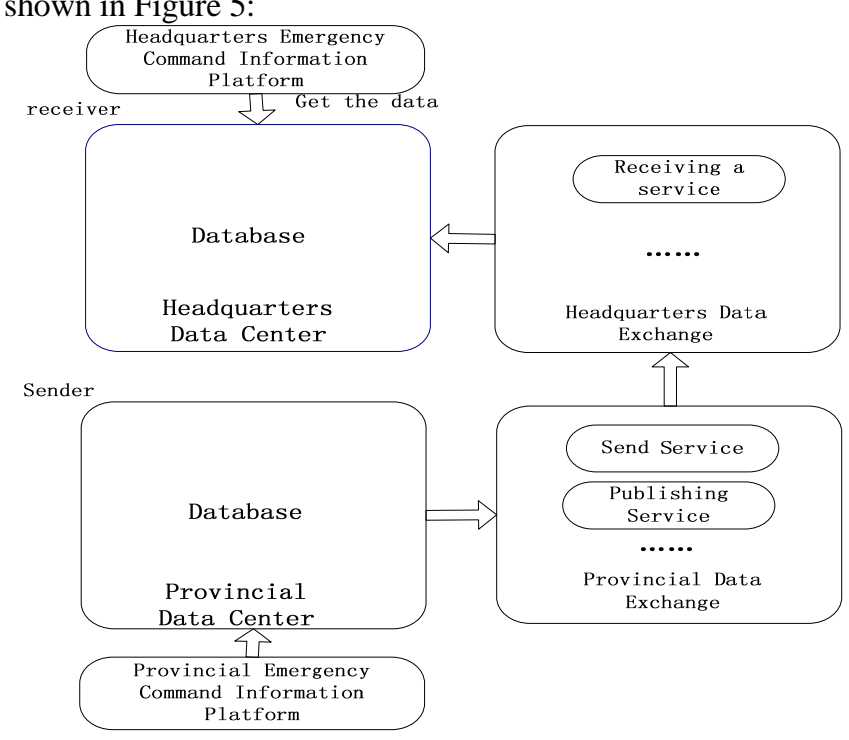

Figure 5. The diagram of the exchange of data from the provincial power to the power company headquarters

Emergency command information platform project team proposed data requirements (data structure, the exchange period) to the data centers and data exchange, data exchange center project team responsible for data center ODS data organization, data exchange project team responsible for the data exchange. Data center project team to the headquarters emergency command information platform that provides connection information (database type, address, user and other information) headquarters data center ODS database and has permission to read data [14] - [15].

\section{A. Exchange process}

Provincial emergency command information platform for data exchange access service calls, send data. Provincial power data exchange platform to exchange data to the headquarters data exchange platform. Headquarters emergency command information platform, monitor data arrival notification queue and promptly determine whether the data arrives, and access to data, analytical data, and information stored in the headquarters of the emergency command platform database [16].

- The premise of exchange process: Headquarters and the provincial power company to complete the design of longitudinal through data related to the unit code must reference unit encoded data of exchange provided; Provincial power companies will provide an interface for data exchange platform and services address to the provincial power company emergency command information platform; Headquarters will provide an interface for data exchange platform service address information to emergency command platform at headquarters.

- Data exchange must field: Data exchange must field shown in Table 4.
TABLE 4. THE MUST FIELD FOR DATA EXCHANGE

\begin{tabular}{|l|l|l|l|l|l|}
\hline $\begin{array}{c}\text { Interface } \\
\text { Field Name }\end{array}$ & $\begin{array}{c}\text { Interface Field } \\
\text { Description }\end{array}$ & Types & Size & $\begin{array}{l}\text { Field } \\
\text { Type }\end{array}$ & Required \\
\hline DEPT_CODE & Unit Coding & CHAR & 18 & $\begin{array}{l}\text { Coded } \\
\text { Field }\end{array}$ & Y \\
\hline TAB_YEAR & Upload Year & NUMBER & 4,0 & $\begin{array}{l}\text { Coded } \\
\text { Field }\end{array}$ & Y \\
\hline $\begin{array}{l}\text { TAB_MONT } \\
\text { H }\end{array}$ & Upload Month & NUMBER & 2,0 & $\begin{array}{l}\text { Coded } \\
\text { Field }\end{array}$ & Y \\
\hline & & & & $\begin{array}{l}\text { Coded } \\
\text { Field }\end{array}$ & Y \\
\hline
\end{tabular}

\section{CONCLUSION}

This paper describes the emergency command information platform longitudinal through data, including: the overall architecture design, based on an exchange format with unformatted data, custom data exchange. Through the program data can be realized through the longitudinal enable commanders to get associated with the event data in a short period of time, in order to make timely decision support, rapid development of contingency plans and measures to dispose of the event, providing a reliable protection.

\section{REFERENCES}

[1] HOU Hui, ZHOU Jian-zhong, ZHANG Yong-chuan, et al. “Analysis of power emergency drills system at home and abroad and its inspiration for China," Power System Protection and Control,2010,38(24): 236-241.

[2] XIE Qiang, LI Jie. “ Current situation of natural disaster in electric power system and countermeasures,” Journal of Natural Disasters, 2006, 15(4): 126-131.

[3] GUO Yong-ji. "To focus on improving power system reliability: A pondering over the East North-America major blackout," Automation of Electric Power Systems, 2003, 27(19): 1-5.

[4] SHI Pei-jun. "Theory on disaster science and disaster dynamics, ”Journal of Natural Disasters, 2002, 11(3): 1-9.

[5] ZHU Chao-yang,YU Zhen,LIU Chao. "Research on theory and technical system for power emergency management, ” Power System Technology, 2011, 35(2): 178-182.

[6] GUO Xiao-ming,LIU Jun-yong. Research on power disaster-relief resources allocation schedule model, " Power System Protection and Control, 2011,39(20): 11-16.

[7] LIAN Bi-zhan, YANG Yang. "Research and design of electric power video surveillance integration platform, " Power System Protection and Control,2011,39(6):11-16.

[8] WANG Cheng-shan, WU Zhen, LI Peng. Research on key technologies of microgrid, " Transactions of China Electrotechnical Society, 2014,29(2):1-12.

[9] YIN Xiang-gen, CHEN Qing-qian, WANG Bo, et al. "Vulnerability assessment system of complicated power system based on four-level set model," Transactions of China Electrotechnical Society, 2013,28(1):255-233.

[10] TIAN Shi-ming, CHEN Xi, ZHU Chao-yang, et al. "Study on electric power emergency management platform,” Power System Technology, 2008, 32(1): 22-27.

[11] ZHOU Jia-qi, ZHAO Xia. "Models and methods applied to risk assessment of power systems,” Electric Power, 2006, 39(8): 77-81.

[12] FENG Yong-qing, ZHANG Bo-ming, WU Wen-chuan, et al. "Power system operation risk assessment based on credibility theory part one propound and development of operation risk assessment," Automation of Electric Power Systems, 2006, 30(1): 17-23. 
[13] XIE Xu-yang, DENG Yun-feng, LI Qun, et al. "Discuss on basic construction of emergency management information system,” Journal of Safety Science and Technology, 2006, 2(6): 27-30.

[14] ZHANG Rong-qian, TAN Zhong-fu, WANG Cheng-wen, et al. “ The risk index system and multi-level risk evaluation model for power supply companies, ” Journal of Electric Power, 2006, 21(2): 123-127.
[15] WANG An-si, LUO Yi, TU Guang-yu, et al. "Real-time initiation approach of emergency control based on fuzzy risk analysis," Transactions of China Electrotechnical Society, 2010, 25(8): 138-144. 